\title{
Viability and Risk Assessment in Species Restoration: Planning Reintroductions for the Wild Boar, a Potential Disease Reservoir
}

\author{
$\underline{\text { Néstor Fernández }}^{1}$, Stephanie Kramer-Schadt ${ }^{2}$, and $\underline{\text { Hans-Hermann Thulke }}^{2}$
}

\begin{abstract}
The reintroduction of large mammals is often considered a priority conservation action in highly industrialized countries in which many of these species have been depleted. However, species reintroduction after decades of absence may involve important risks for human activities and ecological communities, such as favoring the spread of diseases. An example of a potentially troublesome reintroduction is the wild boar, which may act as a reservoir of diseases, e.g., classical swine fever, and cause high economic losses, and has become a species of concern in several European countries for both ecological and recreational reasons. Failure to prevent the disease consequences of species restoration can negate its conservation benefits. Here we evaluated the probability of both successfully reintroducing wild boar into Denmark and limiting their contact with domestic pig farms to which they might spread disease. For this purpose, we developed a spatially explicit, individual-based population model that incorporates information on boar habitat and demography information from Central European populations. We then compared model predictions with the spatial distribution of farms to achieve a spatial assessment of the contact risk. The most restrictive model scenario predicted that nearly $6 \%$ of Denmark provides habitat conditions that would allow wild boar to reproduce. The best habitats for reintroduction were aggregated in seven different areas throughout the country in which the extinction probability was $<5 \%$. However, the expected population expansion was very limited in most of these areas. Both the number of suitable areas and the potential for population expansion greatly increased when we relaxed our habitat assumptions about boar forest requirements; this provided a more conservative scenario for a cautious risk analysis. We additionally found that part of the risk of contact with piggeries was associated with the magnitude of the expansion, although the nonrandom spatial pattern of farm distribution also had a strong influence. The partitioning of risks into those related to population expansion and those related to farm distribution allowed us to identify trade-offs between restoring boar populations and minimizing risks in different potential areas and under different risk scenarios; as a result, we rejected some of the particularly high-risk areas for potential reintroduction of the species. Our approach illustrates how the joint quantification of anticipated reintroduction success and associated risks can guide efforts aimed at reconciling species recovery and the affected health and economic interests.
\end{abstract}

Key Words: conservation; introduced species; risk assessment; rule-based habitat models; spatially explicit population models; species reintroduction; Sus scrofa; wildlife diseases

\section{INTRODUCTION}

Species reintroduction is a key tool for the conservation of animal biodiversity. Often it is considered the only remaining option for ecological restoration in many regions, particularly industrialized countries, in which the native fauna has been decimated and natural recolonizations are unlikely to occur. Examples can be found in Central and Western Europe, where land-use changes and direct persecution have caused the decline and local extinction of numerous vertebrate populations in recent centuries (EEA 2003). Because of their concerns about environmental degradation, presentday societies in these countries are demanding that this "lost nature" be recovered, and national and international conservation policies are increasingly 
regarding the issue of species reintroduction as an added value for both ecosystem and social welfare (IUCN 1998). However, reintroduction after decades of absence may also have a negative impact on ecosystems and on human activities comparable to the introduction, deliberate or not, of alien species. Indeed, reintroductions may conflict with different conservation and economic interests, e.g., if the new population competes with other species or alters their habitats, causes damages to crops, or acts as a disease reservoir (Mack et al. 2000). Therefore, reintroduction planning must be based on a careful identification of the specific negative consequences that it may carry and on estimates of how likely they are to occur (Simberloff et al. 2005).

Among vertebrates, large mammals are often chosen for restoration projects because they face a high extinction risk, because they play key roles in ecological communities, or just because they're "sexy" (Maehr et al. 2001). Consequently, this preference for large mammals is not necessarily a response to global threats but may also reflect aesthetic or recreational values; as a result, programs aiming to restore regional biodiversity often include many widely distributed species with no imminent risk of extinction (Seddon et al. 2005). For example, although the wild boar (Sus scrofa) is a common species in many areas of Europe, Asia, and North Africa and has been introduced into other regions, it is nevertheless a species of conservation concern in several European countries in which it has been depleted. In the last four centuries, wild boars have disappeared or become relict in, e.g., the UK, the Scandinavian countries, and Denmark, as a result of habitat loss caused mostly by deforestation and overhunting. Wild boar recovery has been proposed or already started from captive populations in some of these countries (Howells and Edwards-Jones 1997, Lemel et al. 2003, Alban et al. 2005).

However, reintroducing the wild boar may conflict with different conservation and economic interests, because its populations can alter the community structure and biodiversity of local plants through ground rooting and browsing (Hone 2002, Kuiters and Slim 2002), cause considerable damage to crop fields (Schley and Roper 2003), and transmit diseases to livestock that result in high economic losses (Fritzemeier et al. 2000). Indeed, the wild boar is a potential reservoir of important diseases such as classical swine fever (CSF), a viral disease that has caused highly significant economic losses in Europe (Meuwissen et al. 1999). Boar can infect domestic pigs through direct contact or through human mediation (Artois 2002, de Vos et al. 2003); for example, up to $60 \%$ of CSF outbreaks in domestic pig farms in Germany have been attributed to the cycling of the disease in wild boar populations (Fritzemeier et al. 2000). In turn, wild boar contagion from domestic pigs may also help to propagate the disease and make control more difficult in both wild boar populations and on farms (Artois 2002). Therefore, the role of wild boars as a disease reservoir pits conservation plans against the interests of the farming industry and reveals the need to assess the risks associated with restoration. This assessment requires the development of new methods that take into account both the expected success of the reintroduction and potential conflicts over the affected areas and can guide proactive prevention measures in locations at risk.

In the present study, we evaluated planned reintroductions of wild boar in Denmark together with the associated risk of contact with pig farms. Although these reintroductions are currently under consideration (Alban et al. 2005), there are strong concerns about the potential increase in the CSF risk for the pig-farming industry, one of the most relevant economic activities in the country and one that produces $62.7 \%$ of its annual exports. In this context, restoration efforts need to be preceded not only by an assessment of the likelihood of establishing a free-ranging population but also by measures to prevent the associated negative consequences (IUCN 1998). We first investigated the viability of reintroduced populations using habitat and demographic models. For this we used the available information on wild boar ecology from Central European populations to determine habitat availability and to parameterize an individualbased, spatially explicit model simulating boar demography. This model made possible the explicit consideration of population dynamics in real landscapes with heterogeneous habitat distribution and quality. In a second step, we confronted model simulation results with information on spatial farm distribution to assess the risk of contact between expanding wild boar populations and domestic pigs. Our approach can be adapted to the assessment of other conflicts, such as the alteration of ecosystems, damage to crops, etc., that are associated with the introduction of extinct or alien species, and to the evaluation of population management strategies in relation to these risks. 


\section{METHODS}

\section{Habitat suitability assessment}

Habitat suitability for wild boars was assessed in Denmark based on previous knowledge of the species habitat in Central and Northern Europe. These populations have been shown to be strongly linked to the forests in which they can find primary resources such as food and refuge (Boitani et al. 1994, Groot Bruinderink et al. 1995, Leaper et al. 1999). Forests provide mast, the preferred diet of the wild boars in these regions (Schley and Roper 2003). The species is also reported to take advantage of agricultural landscapes, feeding in crop fields and grasslands mostly in spring and summer (Boitani et al. 1994, Schley and Roper 2003); however, wild boars in these landscapes have been shown to depend on the proximity of woodlands and other sheltering natural vegetation for resting and breeding (Cargnelutti et al. 1990, Gerard et al. 1991). Therefore, wild boar habitat in temperate Europe is mostly characterized by forests and other landscapes in which at least some proportion of woodland can be found. Although there is a lack of studies analyzing minimum vegetation requirements for wild boar, the species can be found in some regions in which only $10 \%$ of the landscape is covered by woodland and other sheltering vegetation.

The density of individuals in Central European wild boar populations is also influenced by the structure of the forests that determine yearly mast productivity and therefore wild boar reproduction and mortality rates (Pucek et al. 1975, Andrzejewski and Jezierski 1978, Groot Bruinderink et al. 1994, Jedrzejewska et al. 1994, Groot Bruinderink et al. 1995, Jedrzejewska et al. 1997). Jedrzejewska et al. (1994) found that the percentage of area covered by stands of deciduous trees explained up to $64 \%$ of the variance in wild boar biomass in exploited forests of Poland. From these data, wild boar density can be related to forest composition using the following regression (Fig. 1):

$y=0.76( \pm 0.44)+0.05( \pm 0.01) \% D e c(1)$

where $y$ is the number of wild boars $/ \mathrm{km}^{2}$ and $\% D e c$ is the percent area covered by deciduous forests. Values in brackets are standard errors.

Based on this information, we modeled the potential distribution of wild boar habitat in Denmark using the following steps:

1. We set the spatial resolution for habitat evaluation at $4 \mathrm{~km}^{2}$, the approximate mean size of the home ranges of a variety of European wild boar populations (Spitz and Janeau 1990). We generated a grid of Denmark composed of $2 \times 2 \mathrm{~km}$ cells to simulate the home ranges of wild boar. The vegetation composition of these cells was identified by matching the grid to a Land Cover Map of Denmark with a 30-m resolution produced from the classification of 20 Landsat TM images spanning the period from 1992 to 1997 (Groom and Stjernholm 2001). We then estimated the percentage of the cell area covered by (1) conifer forest, (2) deciduous and mixed forest, (3) other natural vegetation providing cover, e.g., bush, heathland, etc., and (4) water bodies. The latter class was used to identify barriers to dispersal.

2. Cells with $10 \%$ of their areas covered by forests and natural vegetation were assigned to the category of nonbreeding habitat. However, this minimum amount of forest is probably still not enough for northern wild boar populations, for whom forest can become the only source of food in winter. Therefore, we evaluated alternative scenarios with stricter forest requirements, gradually increasing minimum forest coverage by $5 \%$ up to $50 \%$ of the cell area.

3. Habitat capacity was estimated for each habitat cell based on the proportion of deciduous and mixed forest identified using Eq. 1. The intercept of this equation sets wild boar density for habitats with no deciduous forest. Although wild boars in Central Europe can reach densities well above this value in regions with a low proportion of deciduous trees, this is often because of an artificial food supply in winter, when mast availability plays an important regulatory role in other populations. Our estimates are therefore conservative so that we can detect areas in which a viable wild boar population can persist without an artificial food supply. 
Fig. 1. The relationship between boar density and forest composition found for seven forests in Poland exploited for commercial use (modified after Jedrzejewska et al. 1994).

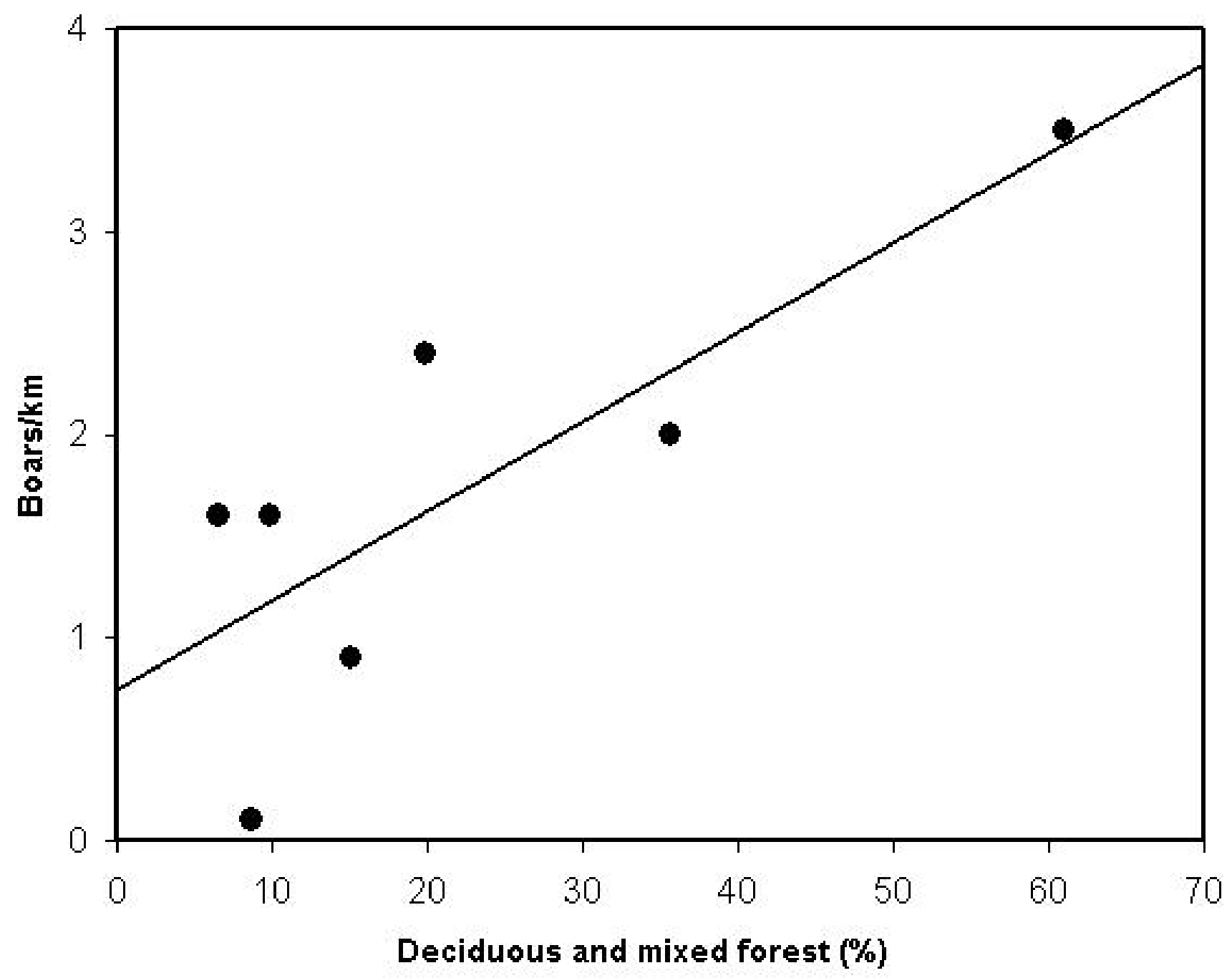

Habitat capacity was used to estimate the potential number of breeding females in the cell, assuming an average ratio of $[N$ breeding females $]:[N$ wild boars $]=1: 4$.

4. The potential distribution of wild-boar home ranges and their quality, i.e., the potential number of breeding females, was mapped for the different scenarios of forest requirements.
The habitat maps provided the basis for simulations of the individual-based population model. 


\section{Simulation of reintroductions and population viability}

We analyzed the viability of reintroductions in different areas of Denmark by means of a spatially explicit, individual-based population model. The model simulates the individual life histories of wild boars in landscapes defined by the generated habitat-suitability maps. It takes into account demographic and environmental stochasticity by means of the different probabilistic demographic events listed below. For simplification, we simulated only female demography and assumed that males did not limit reproduction. Each habitat cell of $4 \mathrm{~km}^{2}$ on the map represents a nonoverlapping core area for a group of female wild boars.

Each individual is subjected to a given probability of survival, breeding, and dispersal at each time step during the simulation, depending on the age of the individual, the density of wild boars in the cell, and the season. The time steps in the model represent weeks. The probabilities were estimated from demographic parameters of wild boar populations studied in France, Italy, Germany, Poland, and Sweden (Table 1).

The sequence and details of the individual lifehistory events were simulated as follows:

\section{Natal dispersal}

Female groups split up at the beginning of the year. Yearling females 34-104 weeks of age disperse if the number of females in the cell exceeds the maximum sustainable number of females. Dispersing females search for nonoccupied habitats to acquire a home range within a distance of three cells from the natal cell, i.e., a $7 \times 7$ cell neighborhood, representing a dispersal distance of $6 \mathrm{~km}$ (Truvé and Lemel 2003). If no empty habitat is available, they stay without breeding in their maternal cell, assuming return movements.

\section{Reproduction}

Females reproduce once a year. The week of reproduction is assigned on the basis of a probability distribution resembling average monthly reproductive rates for wild boar populations in Europe. As seen in Table 1, these typically show a maximum peak during April and May and a minimum of nearly 0 from October to December (Boitani et al. 1995). Females older than 34 weeks are reproductive. The number of breeding females in each cell is limited by the estimated potential density of wild boar. Only older females reproduce if this number is exceeded, in accordance with the hierarchy in female groups. The number of piglets per female is drawn from a Gaussian distribution (see the parameters in Table 1).

\section{Mortality}

The mortality rate of individuals is assigned according to survival rates reported in the literature (Table 1) for piglets < 34 weeks, yearlings, and adults $>104$ weeks. We used mortality rates from hunted populations because recreational hunting is likely to occur after reintroductions. The baseline mortality parameter is assigned at the beginning of each year from the Gaussian distribution of the mean survival rates and their standard deviations (Table 1). In that way we account for the environmental effect of "good" and "bad" years on mortality (Jedrzejewska et al. 1997). This stochasticity has a stronger influence on piglets, the age showing the highest coefficient of variation for survival. If $S_{\mathrm{i}}$ is the random annual survival rate for the age class $i$ in the year, we applied:

$m_{\mathrm{i}}=\left(1-S_{\mathrm{i}}\right)^{1 / 52}$

(2)

where $S_{\mathrm{i}} \sim$ Gaussian (mean survey data ${ }_{\mathrm{i}}$; standard deviation data $\mathrm{a}_{\mathrm{i}}$. The individual in age class $i$ dies according to random realizations of binomial $\left(m_{\mathrm{i}}\right)$. We assume no correlation in baseline mortality among age classes. Simulation experiments showed that this assumption had no effect on population viability estimates as compared with perfectly correlated mortality scenarios.

We released wild boars in the demographic model on different habitat suitability maps. This was done via the following procedure. We iteratively selected one focal habitat cell in the map and the four nearest habitat cells and released on them five wild boar herds with three adult females per herd. We next simulated $50 \mathrm{yr}$ of population dynamics and estimated the number of cells with at least one reproductive female at the end of the simulation. The reintroduction simulation was repeated 100 
Table 1. Wild boar demographic parameters used in the individual-based population model. Mean values are given with standard deviation (SD). Values between brackets indicate the parameter range.

\begin{tabular}{|c|c|c|c|}
\hline $\begin{array}{l}\text { Demographic } \\
\text { parameter }\end{array}$ & Symbol & Model parameter & Source \\
\hline $\begin{array}{l}\text { Maximum age } \\
\text { (yr) }\end{array}$ & $Y_{\max }$ & 11 & $\begin{array}{l}\text { Stubbe et } \\
\text { al.(1989) } \\
\text { Jezierski (1977) }\end{array}$ \\
\hline $\begin{array}{l}\text { Number of } \\
\text { piglets per } \\
\text { female }\end{array}$ & $N_{\text {piglet }}$ & $\begin{array}{l}3.2 \pm 1.68 \mathrm{SD} \\
(0-10)\end{array}$ & $\begin{array}{l}\text { Jezierski (1977) } \\
\text { Focardi et al. } \\
(1996) \\
\text { Boitani et al. } \\
(1995) \\
\text { Ahmad et al. } \\
(1995) \\
\text { Náhlik and } \\
\text { Sándor (2003) } \\
\text { Andrzejewski and } \\
\text { Jezierski (1978) }\end{array}$ \\
\hline $\begin{array}{l}\text { Yearly survival } \\
\text { probability for } \\
\text { piglets }\end{array}$ & $S P_{\text {piglet }}$ & $\begin{array}{l}0.48 \pm 0.37 \mathrm{SD} \\
(0.1-1.0)\end{array}$ & $\begin{array}{l}\text { Focardi et al. } \\
\text { (1996) } \\
\text { Gaillard et al. } \\
(1987)\end{array}$ \\
\hline $\begin{array}{l}\text { Yearly survival } \\
\text { probability } \\
\text { for yearlings } \\
\text { and adults }\end{array}$ & $S P_{\text {adult }}$ & $\begin{array}{l}0.64 \pm 0.24 \mathrm{SD} \\
(0.28-1.0)\end{array}$ & $\begin{array}{l}\text { Stubbe et al. } \\
\text { (1989) } \\
\text { Gaillard et al. } \\
(1987)\end{array}$ \\
\hline $\begin{array}{l}\text { Weekly breeding } \\
\text { probabilities for } \\
\text { females }\end{array}$ & $B P_{\text {month }}$ & $\begin{array}{l}\text { January: } 0.06 \\
\text { February: } 0.1 \\
\text { March: } 0.23 \\
\text { April: } 0.34 \\
\text { May: } 0.07 \\
\text { June: } 0.08 \\
\text { July: } 0.06 \\
\text { August: } 0.03 \\
\text { September: } \\
0.03 \\
\text { October-Dece- } \\
\text { mber: } 0.00\end{array}$ & $\begin{array}{l}\text { Boitani et al. } \\
(1995)\end{array}$ \\
\hline $\begin{array}{l}\text { Distance of } \\
\text { natal dispersal }\end{array}$ & $d_{\text {group }}$ & $\begin{array}{l}\text { Maximum }=6 \\
\mathrm{~km}\end{array}$ & $\begin{array}{l}\text { Truvé and } \\
\text { Lemel (2003) }\end{array}$ \\
\hline
\end{tabular}

times to obtain the percentage of runs in which the model population went extinct, using extinction rate as a measure of reintroduction failure, and the mean number of colonized cells after $50 \mathrm{yr}$ as the rate of population expansion. This process was iterated using every habitat cell in the map as the focal reintroduction cell. The estimated measures of extinction rate and population expansion were finally mapped to obtain a representation of the most favorable areas for wild boar reintroduction in Denmark. We did not investigate alternative reintroduction scenarios because our focus was on the relationship between the success and the risk of reintroduction, rather than the evaluation of different reintroduction strategies. 


\section{Estimation of the relative risk for pig farming}

Wild boars are reported to transmit classical swine fever (CSF) to domestic pigs reared in both closed and extensive open farms. However, larger piggeries are obviously more exposed to contact with wild boars and therefore more prone to CSF transmission across wild and domestic animals. For this reason, we aimed to evaluate the risk of contact between reintroduced wild boars and domestic pigs by analyzing all kinds of pig farms on the one hand and only outdoor/extensive farms on the other. The farm distribution data were obtained from the Central Husbandry Register of the Danish Ministry of Food, Agriculture and Fisheries (

http://www.glr-chr.dk). This is a comprehensive database containing information on all Danish farming properties.

We considered farms to be at risk if located within the $3 \times 3$ cell neighborhood of a cell in which reproduction occurred during the simulation period; this was taken to be a signal of herd establishment. This buffer was adequate to estimate the risk of CSF neighborhood infections, i.e., not mediated by human transport, which decreases from the source of the infection down to $500 \mathrm{~m}$ in domestic pigs (Staubach et al. 1997, Crauwels et al. 2003). For every simulated reintroduction, the contact risk was estimated as the number of farms in these buffers averaged over the 100 simulations. The risk measure was mapped for all cells to achieve a spatial risk representation. We expected a correlation between the mean number of farms at risk and the population expansion, because more farms would be affected with higher wild-boar colonization. However, the heterogeneous distribution of farms may also influence spatial variations in risk. In this case, the residuals of the relation between risk estimation and population expansion revealed the effect of spatially nonrandom patterns in farm distribution. To measure this effect, we compared the risk estimated from the original simulations with a null model simulating the same population expansion in landscapes with random farm distribution. A Monte Carlo approach was performed by randomizing the farm locations on the map before the population dynamics and remeasuring the number of farms at risk at the end of the simulation period. The randomization procedure was repeated 100 times per reintroduction to estimate the full distribution of the number of farms at risk under the assumption of randomly located farms.
Finally, we determined the probability value of the original farm assemblage in the Monte Carlo distribution and assigned the corresponding percentile score to the focal cell. These scores were mapped to visualize the trade-off between reintroduction success and relative risk to farms in the different reintroduction areas.

\section{RESULTS}

\section{Distribution of potential habitats in Denmark}

Potential wild boar habitat in Denmark represented more than $40 \%$ of the total area under the more relaxed assumption of $10 \%$ forest cover requirements. However, only $22.7 \%$ of the country showed the expected wild boar density of more than one individual per square kilometer $\left(1 / \mathrm{km}^{2}\right)$, the minimum density found throughout many European populations (e.g., see revisions by Howells 1997, Leaper 1999). Habitat prediction was very sensitive to assumptions regarding minimum forest-cover requirements (Fig. 2), to the extent that only $5.7 \%$ of the study area is potential habitat if $50 \%$ cover is assumed. Larger requirements would imply even lower habitat availability and, in that case, reintroduction programs would probably not succeed. Habitats with expected wild boar densities of $<1 / \mathrm{km}^{2}$ always represent approximately $50 \%$ of the total habitat under all assumptions about forest coverage (Fig. 2). This indicates that, in general, forests in Denmark are not likely to sustain high densities of wild boars.

\section{Viability of the reintroduction}

The success in terms of population persistence of simulated wild boar reintroductions differed greatly among focal release areas (Fig. 3). Holding to the most restrictive assumption of $50 \%$ forest required for home range acquisition (Fig. 3B), the spatially explicit demographic model predicted an aggregation of suitable reintroduction cells around four areas in the Jutland Peninsula and two in Sealand in which wild boar populations would persist with a probability of $>95 \%$. However, Central Jutland and North Sealand were the only areas in which simulations resulted, on average, in population expansions larger than four times the initial population (Fig. 3D). The number of 
Fig. 2. Proportion of area covered by wild boar habitat in the study areas of Denmark in relation to minimum forest requirements in home ranges. Black sticks represent the proportion of area with estimated boar density $>1 / \mathrm{km}^{2}$.

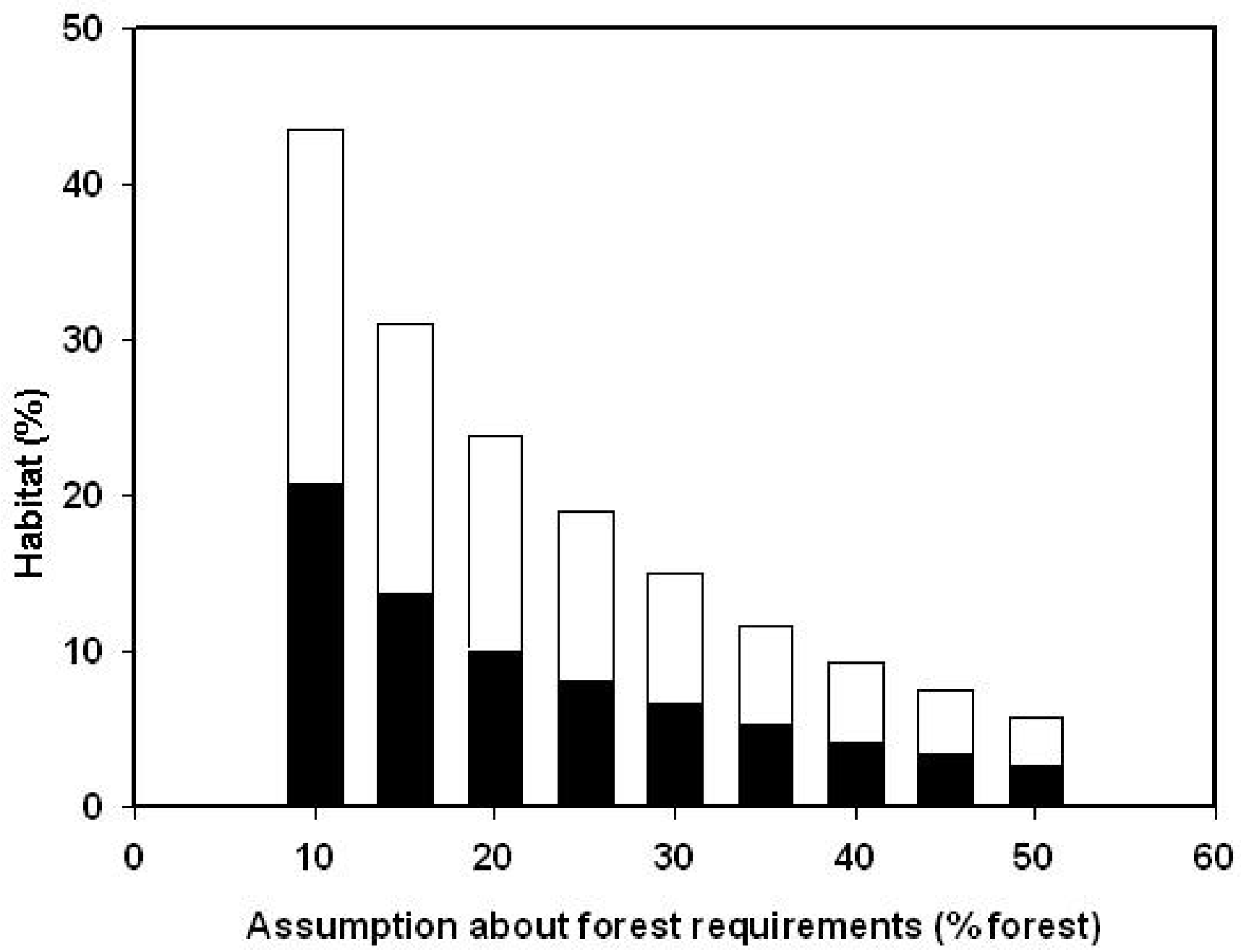

favorable reintroduction locations greatly increased as the required forest assumption was relaxed, with a maximum expansion of $640 \mathrm{~km}^{2}$ after $50 \mathrm{yr}$ of simulation under the most optimistic scenario.

Reintroduction success was associated with habitat availability, i.e., the number of habitat cells around the place of release, and with breeding capacity, $i$. e., the maximum possible number of breeding females within those cells (Fig. 4). For the most restrictive habitat scenario of $50 \%$ forest, the highest correlations between extinction rate and habitat variables occurred at scales between a radius of 11 and $17 \mathrm{~km}$. This suggests that reintroduction success will depend on the availability of high-quality habitats over areas $\geq 380 \mathrm{~km}^{2}$. As seen in Fig. 4B, the correlation with breeding capacity was stronger (Spearman's correlation: $p \leq-0.60$ between scales 11 and 15), indicating that, beyond habitat availability, quality plays also a primary role in guaranteeing successful reintroductions. With respect to population expansion, the highest 
Fig. 3. Extinction probability from 0 to 1 and expected population expansion, i.e., number of cells colonized divided by five or the number of release cells, for releases in each focal wild boar reintroduction cell in Denmark. Maps A and C assume that cells with $\geq 10 \%$ forest provide breeding habitat to wild boars; in B and $\mathrm{D}$, only cells with $\geq 50 \%$ forest are habitat.
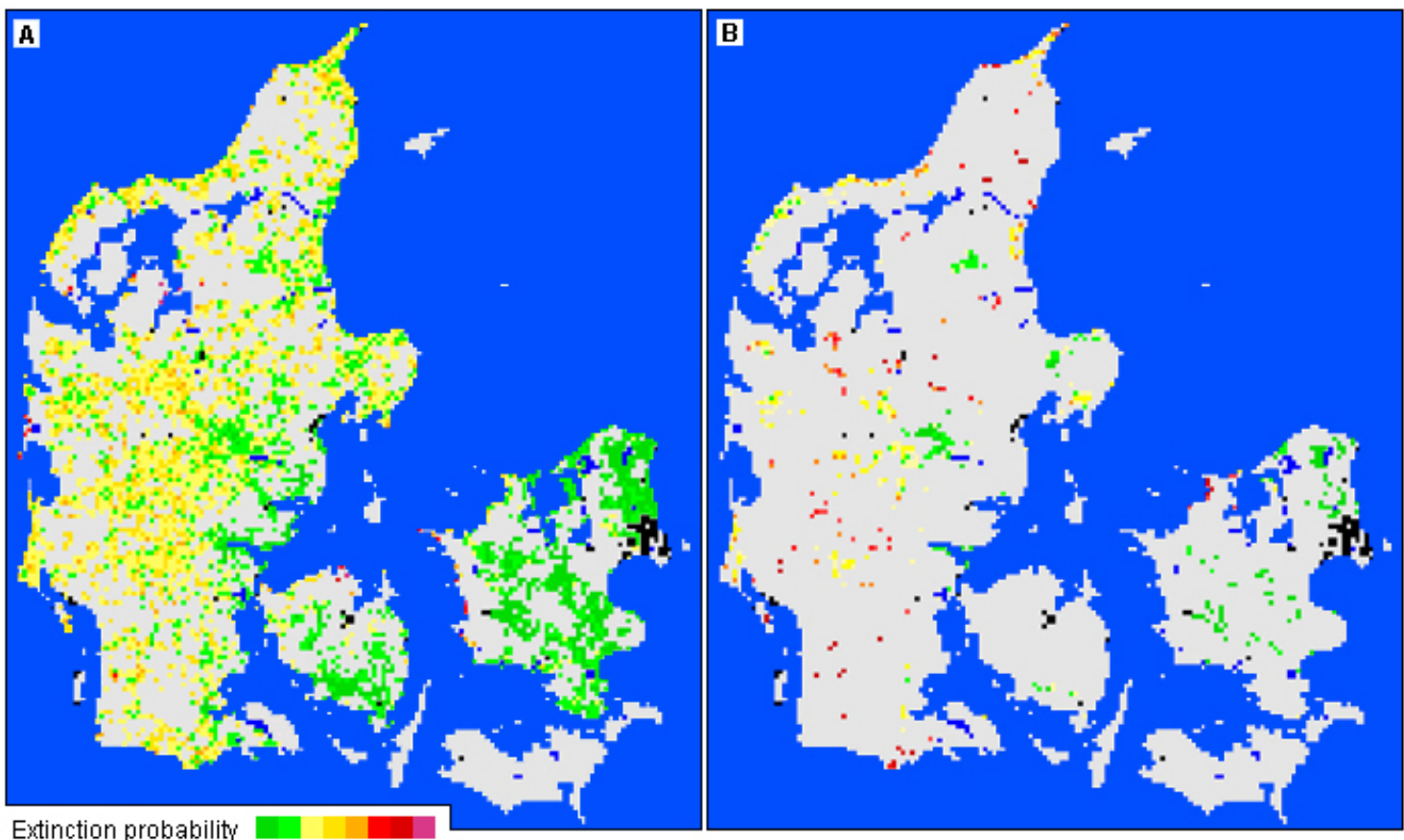

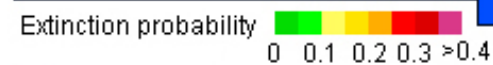
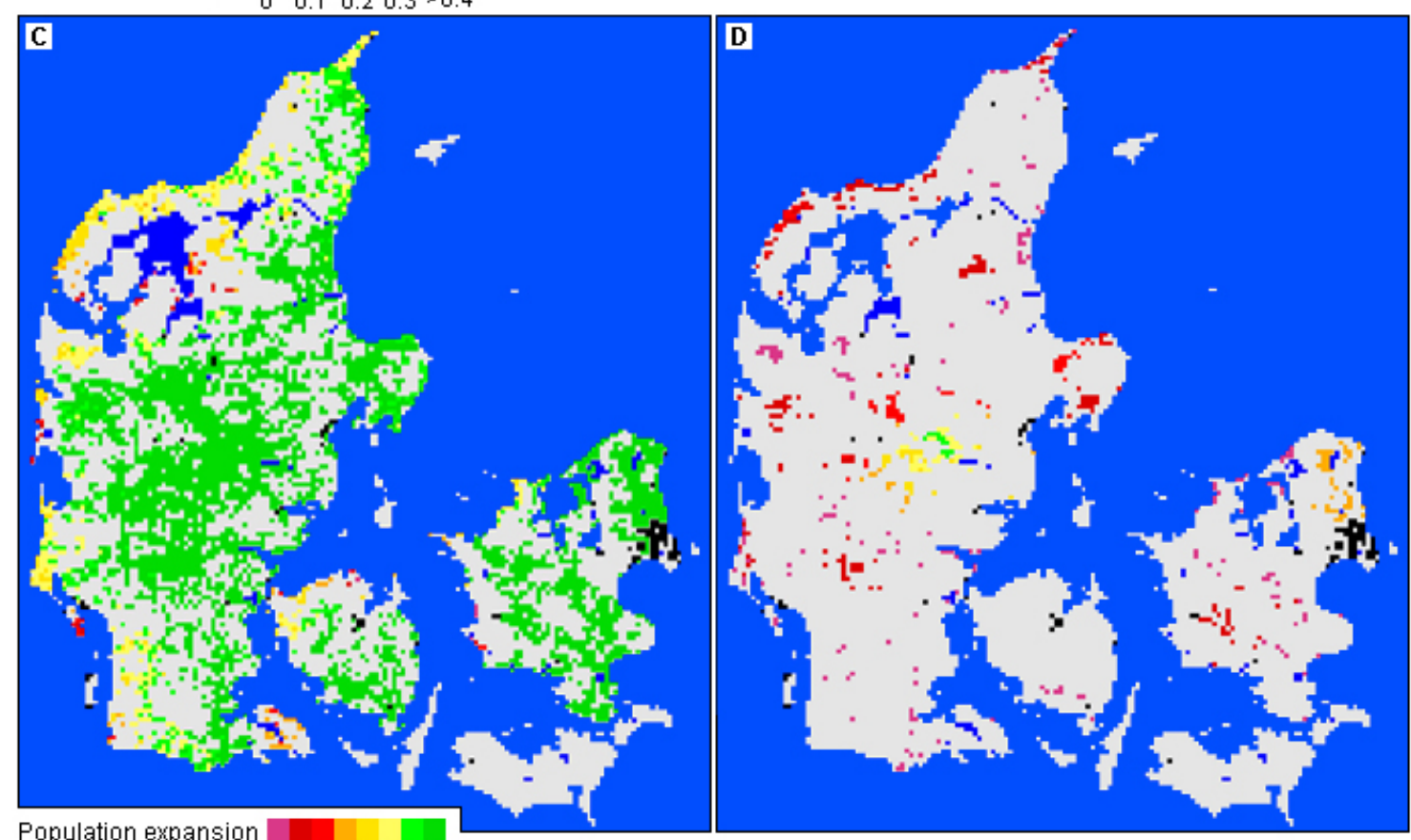

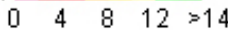


Fig. 4. Wild boar reintroduction success in relation to habitat availability, i.e., number of habitat cells, and quality, i.e., breeding capacity of these cells, in a radial neighborhood of different scales. A and B represent population expansion or number of cells colonized in relation to habitat availability and quality, respectively; $\mathrm{C}$ and $\mathrm{D}$ represent extinction probability in relation to the same variables. Black squares: $50 \%$ forest coverage required; white squares: $10 \%$ forest coverage required. The number of habitat cells in a given subarea is related to the proportion of forest in a particular landscape, whereas breeding capacity is influenced by the composition of the forest.
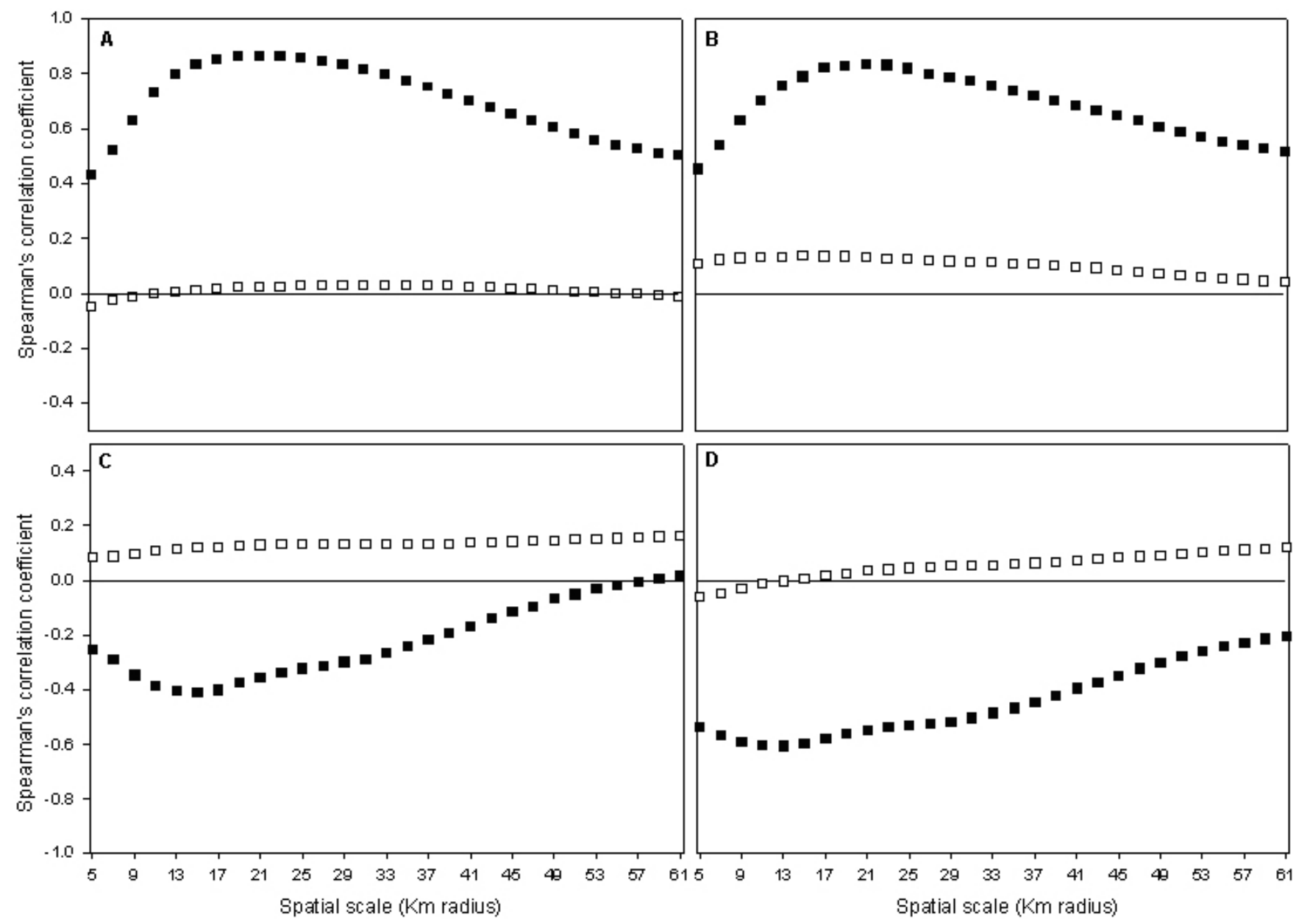

correlations were observed with habitat availability at spatial scales between a radius of 17 and $27 \mathrm{~km}$ $(p \geq 0.85)$, as seen in Fig. 4C.

The outcome of simulated reintroductions under the most optimistic habitat assumption was only weakly correlated with habitat availability and quality at any spatial scale (all $p<0.14$ ), indicating that habitat was not limiting in this scenario.

\section{Farms at risk}

The number of farms at risk was moderately correlated with the population expansion in the scenario with a forest requirement of $10 \%(p=0.69$, $P<0.001$ in all farms and in extensive farms), and only weakly when the forest requirement was $50 \%$ (all farms: $p=0.55, P<0.001$; extensive farms: $p$ $=0.29, P<0.001)$. Additionally, we found that the 
aggregated distribution of farms had a strong effect on the contact probability with reintroduced wild boars. This is shown by the fact that the number of affected farms differed greatly from the predictions of the simulated expansions in the random farmdistribution scenario.

We based our geographical risk analysis on a cautious approach by investigating the scenario that results in a larger expansion of the wild boar population, i.e., the $10 \%$ forest requirement (Figs. $5 \mathrm{~A}$ and $5 \mathrm{~B}$ ). In general, the number of extensive farms at risk was low compared with the total number of farms, with a maximum of 26 extensive farms contacted by a colonizing wild boar population. In contrast, some scenarios resulted in more than 300 farms at risk when closed piggeries were also included. The highest number of farms in contact with wild boars was associated with releases in the middle of Jutland in the Silkeborg Forest and in Sealand.

However, population expansion did not completely account for the number of farms at risk. For example, when we compared the risk in northern Sealand with the results of the Monte Carlo simulations of the null model, we found that fewer farms were affected than expected from the sole effect of population expansion, whereas the opposite was observed in the northeast of Jutland (Fig. 5C). In some areas the estimated risk depended on the type of farm considered. With regard only to outdoor farms, northern Sealand becomes less favorable for reintroduction because of the disproportionate risk of contact in relation to the wild boar expansion (Fig. 5D). For the same reason, Fyn Island and a large area in the west of Jutland are not suitable either.

Figure 6 summarizes the trade-off between population expansion under the most restrictive habitat scenario and the relative risk to farms for the areas in which the extinction probability of the reintroduced populations was low, i.e., < $5 \%$. Cautious reintroduction options are reduced to three small areas in the north of Jutland in which the expansion is much smaller but the risk of contact to farms is relatively low. The risk is proportional to the expansion in Central Jutland, the most favorable area for achieving the reintroduction objectives.

\section{DISCUSSION}

Species restoration must be founded on prior assessments of population viability and associated risks, which are only possible when there is a clear understanding of the interactions between the demographic traits of the species and the landscapes designated as targets for reintroduction. Based on this premise, we developed a spatially explicit approach to quantify both the reliability of wild boar reintroductions in Denmark and their risks for the pig-farming industry. Based on the assumption that appropriate habitats would contain at least $50 \%$ forest, only $22 \%$ of the potential release sites were found to be suitable for achieving a population containing more than 100 breeding females, whereas most of the simulations reached this number if the proposed site contained only $10 \%$ forest. Given this variability, wild-boar recovery plans should consider the most restrictive scenario for the selection of release areas to maximize the probability of reintroduction success. Using this criterion, we identified up to seven potential areas with low extinction probability, i.e., $<5 \%$ under the restrictive scenario, distributed in Sealand and in the centre of Jutland, in which simulated populations expanded over larger areas. Future landscape changes are not projected in these results, although they can be relevant for reintroduction success (Carroll et al. 2003); for example, there are conservation plans for increasing forest cover in Denmark that will likely favor wild-boar habitat availability in the future (Alban et al. 2005). However, we were interested in discovering the most suitable areas for reintroduction under current conditions so that managers can incorporate our predictions before forest recovery plans go into effect.

The outcome of reintroductions was strongly associated with both the availability and the mean quality of the habitats for reproduction around release sites. In our model, the expansion of reintroduced populations was a consequence of female dispersal and home range acquisition in unoccupied habitat cells. Landscapes with a low proportion of suitable habitat resulted in reduced connectivity, which made it harder for dispersing individuals to acquire a home range and led to small populations more vulnerable to extinction, particularly in the most restrictive habitat scenario. However, habitat quality also played a major role in population persistence, as shown by the higher correlation coefficients between extinction rate and 
Fig. 5. Contact risk between breeding wild boars and pig farms in Denmark as obtained from the simulation model. Colors represent the estimated risk from releases in each of the focal reintroduction cells. (A) Total number of farms in buffer areas of one cell around habitats in which boars breed, averaged for all simulations in each reintroduction cell; (B) same for extensive and other outdoor farms; (C) and (D) outlier distribution of farms at risk as compared to the null model of random farm distribution. Colors represent the percentile score of the estimated risk.
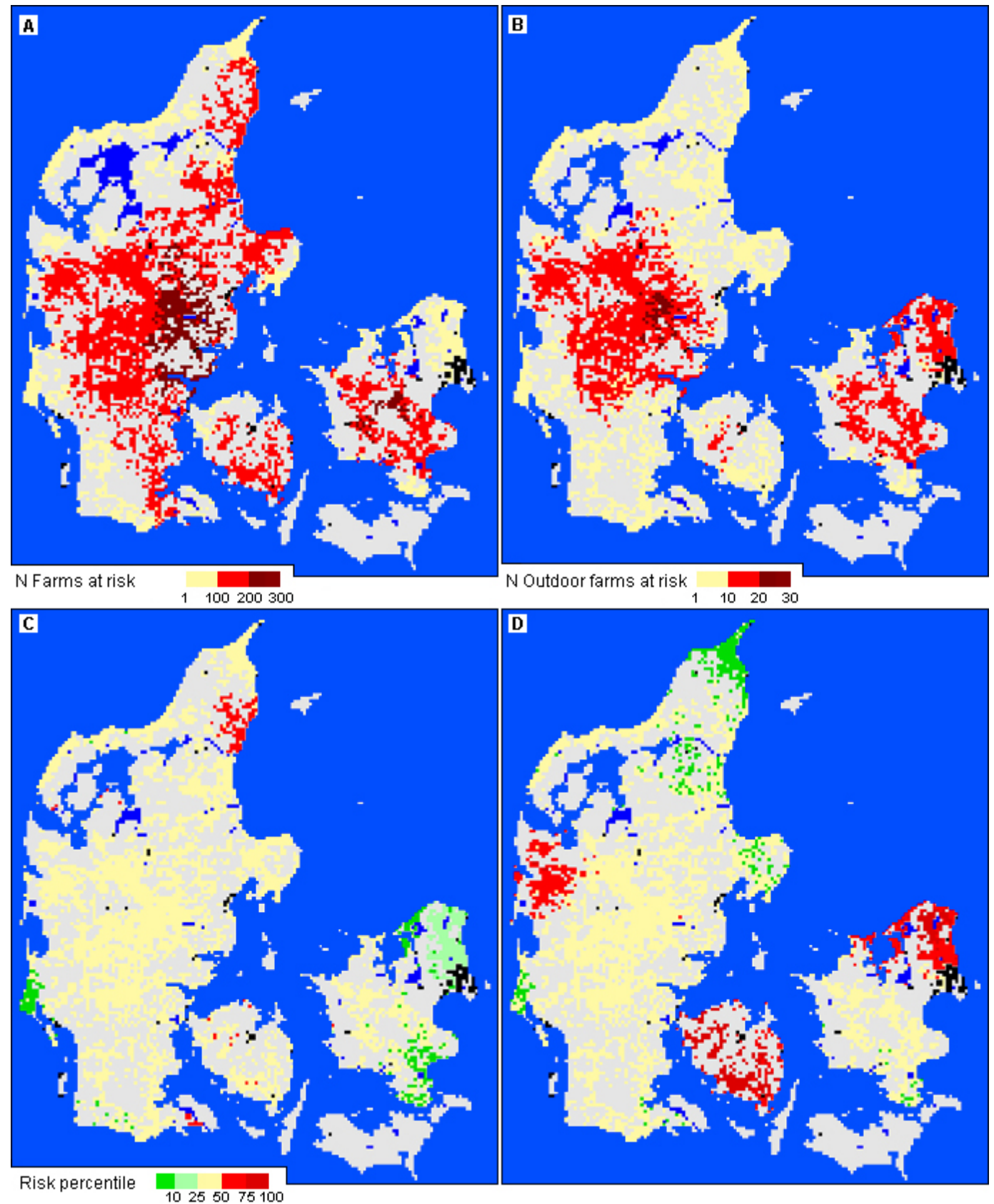
Fig. 6. Classification of potential reintroduction areas in Denmark attending to the most restrictive habitat scenario for boar reintroduction success, i.e., high forest requirement, and the most pessimistic risk scenario, i.e., boars also expand and contact farms thorough areas with low forest cover. Area type: (A) high population expansion, high risk relative to the expansion; (B) high expansion, proportional risk; (C) low expansion, high relative risk; and (D) low expansion, proportional to low relative risk. Area: (1) North Sealand, (2) South Sealand, (3) Fynn Island, (4) Silkeborg Forest, (5) Djursland Peninsula, (6) Rold Forest, and (7) Thy.

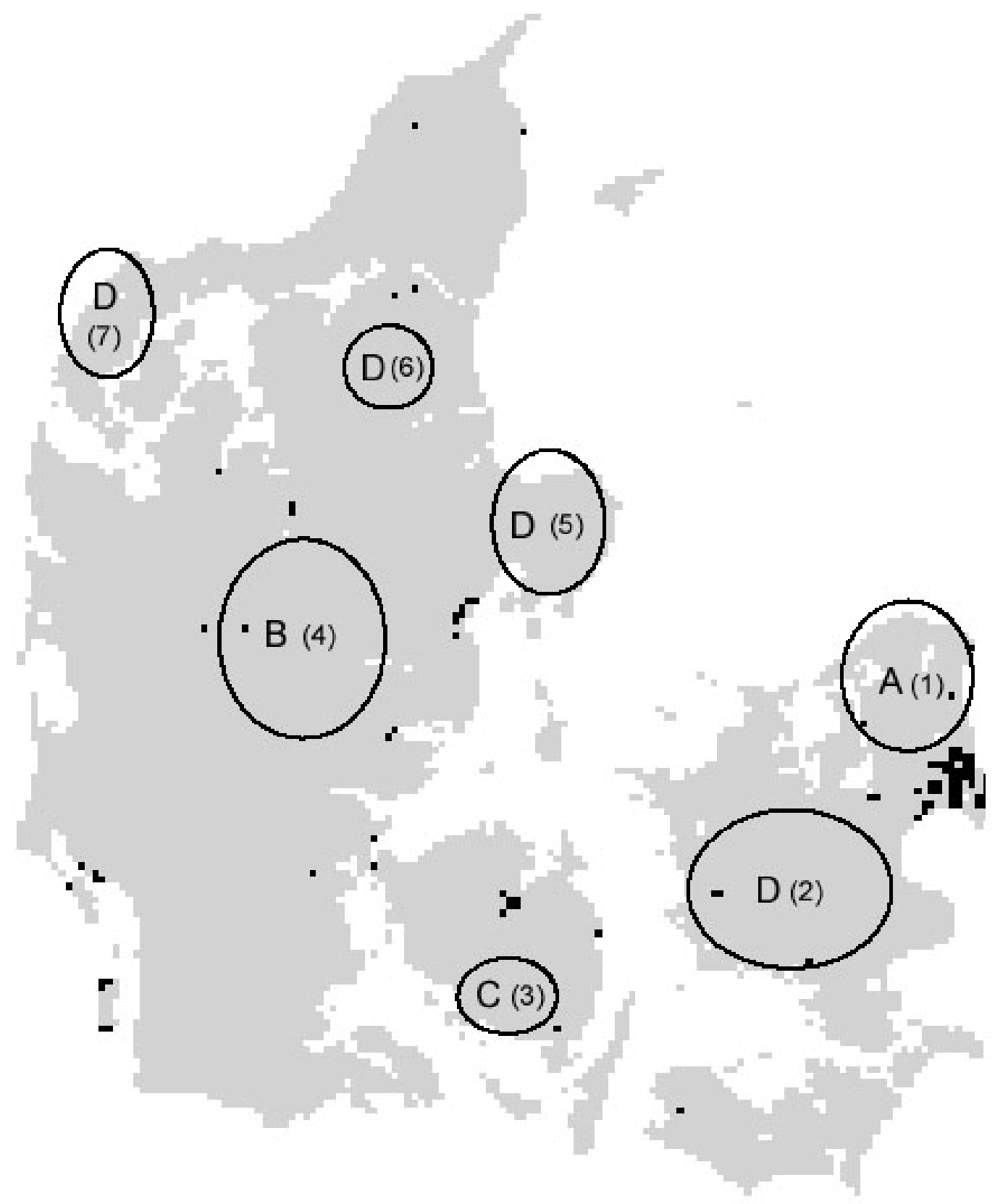


potential female density. High-quality habitats represent an increased capacity for reproductive individuals, allowing the persistence of larger populations in reduced areas. This explains the low extinction rates in most focal reintroduction areas of Sealand as compared with the Jutland Peninsula, even though population expansion was generally larger in the latter. These results reveal the need to consider not only habitat distribution and size but also spatial variations in habitat quality that may influence the reproductive performance of individuals when assessing species reintroduction success and population viability in general (Wiegand et al. 1999).

The conservation purpose of achieving an expanding wild-boar population clearly conflicts with health and economic concerns related to the potential transmission of disease between wild boars and domestic pigs, particularly classical swine fever (Artois et al. 2002, Alban et al. 2005). We observed that the number of farms in contact with an expanding wild-boar population was only partly correlated with the size of the expansion. Indeed, the spatial pattern of farm distribution had also a strong effect. This finding suggests that the restoration of wild boar in some areas would entail a higher risk compared with the reintroduction goals. Partitioning the risk contributed by population expansion and the distribution of exposed farms made it possible to evaluate the tradeoffs between maximizing restoration and minimizing risk. This distinction is critical for optimizing preventive measures, like those intended to inhibit contact between domestic and wild pigs.

The distribution of high-risk areas differed depending on whether all or only outdoor farms were considered, both in absolute terms as well as in relation to the expected population expansion. One controversial result is that Northern Sealand, one of the most suitable regions for reintroducing the species, was a high-risk area for outdoor farms in relation to the expected expansion (Fig. 6). This risk was not manifest when all types of farms were included in the evaluation: the total number of farms potentially in contact with wild boars was noticeably low both in absolute and relative terms. Results also advise against reintroductions in Fyn Island because of the high relative density of outdoor farms. Under this criterion, only some peripheral areas of Jutland represent a low risk both in absolute and relative terms, although the strictest habitat scenario also predicts a high probability of failure in reintroducing the species in most of them. Central Jutland provides, under all scenarios, the best conditions for an expanding wild boar population and a proportional risk of contact with farms. This area is probably the most convenient for the species' restoration, although the large expected expansion will require significant preventive efforts to effectively isolate wild boars and domestic pigs on a high number of outdoor farms.

Evaluating habitat availability and connectivity for reintroduction is often problematic because of the lack of data on habitat associations and demography for the areas in which the species went extinct (Kramer-Schadt et al. 2005). We have shown that the incorporation of ecological knowledge from other persisting populations can help in developing predictive habitat and population models to assess the viability of wild boar reintroduction under these constraints. However, incomplete knowledge of habitat selection and dispersing behavior may represent a limitation. For example, we did not consider the effects on dispersal movement in the matrix (Wiegand et al. 2005) of either landscape structures or barriers other than water bodies, such as fences, roads, etc., which could lower the viability of reintroduced populations and limit their expansion and the associated risks. In this sense, the detailed monitoring of the population after reintroduction is essential to evaluate model predictions with regard to both viability and risk and to update the models as data from the new population become available (Bar-David et al. 2005). Other parameters such as mortality may vary greatly among populations depending on factors such as hunting pressure. Therefore, the monitoring of these parameters is also crucial and may help to redesign population management strategies to attain the goals of restoration while minimizing associated risks.

This study focused on the potential contact between wild boars and domestic pigs that could involve the risk of disease transmission, particularly classical swine fever (CSF). The most likely pathways of CSF infection in wild boar are spread from other populations and contact with infected domestic pigs, including insufficient prophylactic measures during pig handling (Fritzemeier et al. 2000). However, our lack of knowledge about the population-related factors that affect disease persistence in wild boar limits our ability to assess risks from reintroductions that may result, for example, in different population sizes. Larger 
population size (Artois et al. 2002) and density (Rossi et al. 2005) may increase CSF persistence in the wild boar, but the disease has also circulated in small foci and at low densities of 1-3 individuals/ $\mathrm{km}^{2}$ (Laddomata et al. 1994, Guberti et al. 1998). This implies that virtually all viable populations in Denmark involve some risk of endemic disease in the event of infection, although the most successful reintroductions involving larger population sizes and higher densities will likely provide better conditions for the persistence of the disease.

In summary, the joint quantification of the expected success and risks represents a promising contribution in species restoration that is only possible in the framework of spatially explicit models that incorporate an in-depth understanding of the life-history traits of the species. The individual-based approach made it possible to model the population expansion and its associated risks in the absence of previous demographic data, an inherent drawback in reintroduction studies. We believe that this approach can help to overcome the "unpredictability of introduction impacts" (Simberloff et al. 2005), not only in species restoration but also in the introduction of alien species, deliberate or not.

Responses to this article can be read online at:

http://www.ecologyandsociety.org/vol11/iss 1/art6/responses/

\section{Acknowledgments:}

We thank Lis Alban for her introduction to the topic of wild boar reintroduction in Denmark, and Mette Marie Andersen for her support with the Danish pig farm database. We are also thankful and want to acknowledge the fruitful discussions about the model construction we had with Jürgen Teuffert, Christoph Staubach, Matthias Greiner, Anders Stockmeyer, and Tommy Asferg. Comments from Jane U. Jepsen and two anonymous referees helped to improve previous versions of the manuscript. NF was supported by a Marie Curie Host Fellowship provided by the European Commission (HPMDCT-2001-00109).

\section{LITERATURE CITED}

Ahmad, E., J. E. Brooks, I. Hussain, and M. H. Khan. 1995. Reproduction in Eurasian wild boar in central Punjab, Pakistan. Acta Theriologica 40:163-173.

Alban, L., M. M. Andersen, T. Asferg, A. Boklund, N. Fernández, S. G. Goldbach, A. Greiner, A. Højgaard, S. Kramer-Schadt, A. Stockmarr, H.-H. Thulke, A. Uttenthal, and B. Ydesen. 2005. Classical swine fever in wild boars: a risk analysis. Danish Institute for Food and Veterinary Research DFVF, Copenhagen, Denmark. Available online at:

http://www.dfvf.dk/Files/Filer/EpiLab/WILDRISK_2005. pdf

Andrzejewski, R., and W. Jezierski. 1978. Management of a wild boar population and its effects on commercial land. Acta Theriologica 23:309-339.

Artois, M., K. R. Depner, V. Guberti, J. Hars, S. Rossi, and D. Rutili. 2002. Classical swine fever (hog cholera) in wild boar in Europe. Revue Scientifique et technique de l'Office International des epizooties 21:287-303.

Bar-David, S., D. Saltz, T. Dayan, A. Perelberg, and A. Dolev. 2005. Demographic models and reality in reintroductions: Persian fallow deer in Israel. Conservation Biology 19:131-138.

Boitani, L., L. Mattei, D. Nonis, and F. Corsi. 1994. Spatial and activity patterns of wild boars in Tuscany, Italy. Journal of Mammalogy 75:600-612.

Boitani, L., L. Trapanese, L. Mattei, and D. Nonis. 1995. Demography of a wild boar (Sus scrofa L.) population in Tuscany, Italy. Gibier Faune Sauvage 12:109-132.

Cargnelutti, B., J. F. Gerard, F. Spitz, G. Vale, and T. Sardin. 1990. Wild boar (Sus scrofa) occupation of habitat in a by farm-mechanization modified agro-ecosystem. Gibier Faune Sauvage 7:53-66.

Carroll, C., M. K. Phillips, N. H. Schumaker, and D. W. Smith. 2003. Impacts of landscape change on wolf restoration success: planning a reintroduction program based on static and dynamic spatial models. Conservation Biology 14:536-548. 
Crauwels, A. P. P., M. Nielen, A. R. W. Elbers, J. A. Stegeman, and M. J. M. Tielen. 2003. Neighborhood infections of classical swine fever during the 1997-1998 epidemic in The Netherlands. Preventive Veterinary Medicine 61:263-277.

de Vos, C. J., H. W. Saatkamp, and A. A. Dijkhuizen. 2003. The risk of the introduction of classical swine fever at regional level in the European Union: a conceptual framework. Revue Scientifique et technique de l'Office International des epizooties 22:795-810.

European Environment Agency (EEA). 2003. Europe's environment: the third assessment. EEA, Copenhagen, Denmark.

Focardi, S., S. Toso, and E. Pecchioli. 1996. The population modelling of fallow deer and wild boar in a Mediterranean ecosystem. Forest Ecology and Management 88:7-14.

Fritzemeier, J., J. Teuffert, I. Greiser-Wilke, C. Staubach, H. Schluter, and V. Moennig. 2000. Epidemiology of classical swine fever in Germany in the 1990s. Veterinary Microbiology :29-41.

Gaillard, J. M., J. Vassant, and F. Klein. 1987. Quelques charactéristiques de la dynamique des populations de sangliers (Sus scrofa scrofa) en milieu chassé. Gibier Faune Sauvage

4:31-47.

Gerard, J. F., B. Cargnelutti, F. Spitz, G. Valet, and T. Sardin. 1991. Habitat use of wild boar in a French agroecosystem from late winter to early summer. Acta Theriologica 36:119-129.

Groom, G., and M. Stjernholm. 2001. The Area Information System (AIS): a Danish national spatial environmental database. Pages 81-87 in G. Groom and T. Reed, editors. Strategic landscape monitoring for the Nordic countries. Nordic Council of Ministers, Copenhagen, Denmark.

Groot Bruinderink, G. W. T. A., G. Bruinderink, and E. Hazebroek. 1995. Modelling carrying capacity for wild boar Sus scrofa scrofa in a forest/ heathland ecosystem. Wildlife Biology

1:81-87.

Groot Bruinderink, G. W. T. A., E. Hazebroek, and H. van der Voot. 1994. Diet and conditioning of wild boar, Sus scrofa scrofa, without supplementary feeding. Journal of Zoology 233:631-648.

Guberti, V., D. Rutili, G. Ferrari, C. Patta and A. Oggaino. 1998. Estimate the threshold abundance for the persistence of the classical swine fever in the wild boar population of the eastern Sardinia. Report on measures to control classical swine fever in European wild boar. Document VI/7196/98-AL. Commission of the European Communities, Directorate General VI for Agriculture, Perugia, Italy.

Hone, J. 2002. Feral pigs in Namadgi National Park, Australia: dynamics, impacts and management. Biological Conservation

105:231-242.

Howells, O., and G. Edwards-Jones. 1997. A feasibility study of reintroducing wild boar Sus scrofa to Scotland: Are existing woodlands large enough to support minimum viable populations? Biological Conservation 81:77-89.

Jedrzejewska, B., W. Jedrzejewski, A. N. Bunevich, L. Milkowski, and Z. A. Krasinski. 1997. Factors shaping population densities and increase rates of ungulates in Bialowieza Primeval Forest (Poland and Belarus) in the 19th and 20th centuries. Acta Theriologica 42:399-451.

Jedrzejewska, B., H. Okarma, W. Jedrzejewski, and L. Milkowski. 1994. Effects of exploitation and protection on forest structure, ungulate density and wolf predation in Bialowieza Primeval Forest, Poland. Journal of Applied Ecology 31:664-676.

Jezierski, W. 1977. Longevity and mortality rate in a population of wild boar. Acta Theriologica 22:337-348.

Kramer-Schadt, S., E. Revilla, and T. Wiegand. 2005. Lynx reintroductions in fragmented landscapes of Germany: projects with a future or misunderstood wildlife conservation? Biological Conservation 125:169-182.

Kuiters, A. T., and P. A. Slim. 2002. Regeneration of mixed deciduous forest in a Dutch forestheathland, following a reduction of ungulate densities. Biological Conservation 105:65-74.

Laddomada, A., C. Patta, A. Oggiano, A. Caccia, 
A. Ruiu, P. Cossu and A. Firinu. 1994. Epidemiology of classical swine fever in Sardinia: a serological survey of wild boar and comparison with African swine fever. Veterinary Microbiology 134:183-187.

Leaper, R., G. Massei, M. L. Gorman, and R. Aspinall. 1999. The feasibility of reintroducing wild boar (Sus scrofa) to Scotland. Mammal Review 29:239-259.

Lemel, J., J. Truvé, and B. Söderberg. 2003. Variation in ranging and activity behavior of European wild boar Sus scrofa in Sweden. Wildlife Biology 9:29-36.

Mack, R. N., D. Simberloff, W. M. Lonsdale, H. Evans, M. Clout, and F. A. Bazzaz. 2000. Biotic invasions: causes, epidemiology, global consequences, and control. Ecological Applications 10:689-710.

Maehr, D. S., R. F. Noss, and J. L. Larkin. 2001. Large mammal restoration: ecological and sociological challenges in the 21st century. Island Press, Washington D.C., USA.

Meuwissen, M. P. M., H. S. Horst, R. B. M. Huirne, and A. A. Dijkhuizen. 1999. A model to estimate the financial consequences of classical swine fever outbreaks: principles and outcomes. Preventive Veterinary Medicine 42:249-270.

Náhlik, A., and G. Sándor. 2003. Birth rate and offspring survival in a free-ranging wild boar Sus scrofa population. Wildlife Biology 9:37-42.

Pucek, Z., B. Bobek, L. Labudski, L. Milkowski, K. Andrzej, and T. Andrzej. 1975. Estimates of density and number of ungulates.

Polish Ecological Studies 1:121-135.

Rossi, S., E. Fromont, D. Pontier, C. Cruciere, J. Hars, J. Barrat, X. Pacholek and M. Artois. 2005. Incidence and persistence of classical swine fever in free-ranging wild boar (Sus scrofa).

Epidemiology and Infection 133:559-68.

Schley, L., and T. J. Roper. 2003. Diet of wild boar Sus scrofa in Western Europe, with particular reference to consumption of agricultural crops. Mammal Review 33:43-56.

Seddon, P. J., P. S. Soorae, and F. Launay. 2005. Taxonomic bias in reintroduction projects. Animal
Conservation 8:51-58.

Simberloff, D., I. M. Parker, and P. N. Windle. 2005. Introduced species policy, management, and future research needs. Frontiers in Ecology and the Environment 3:12-20.

Spitz, F., and G. Janeau. 1990. Spatial strategies: an attempt to classify daily movements of wild boar. Acta Theriologica

35:129-149.

Stauback, C., J. Teuffert, and H. H. Thulke. 1997. Risk analysis and local spread mechanisms of classical swine fever. Pages 31-32 in Proceedings of the Eigth Symposium of the International Society for Veterinary Epidemiology and Economics (Paris, 1997). International Society for Veterinary Epidemiology and Economics, s.l.

Stubbe, C., S. Mehlitz, R. Peukert, J. Goretzki, W. Stubbe, and H. Meynhardt. 1989. Lebensraumnutzung und Populationsumsatz des Schwarzwildes in der DDR-Ergebnisse der Wildmarkierung. Beiträge zur Jagd-und Wildforschung 16:212-231.

Truvé, J., and J. Lemel. 2003. Timing and distance of natal dispersal for wild boar Sus scrofa in Sweden. Wildlife Biology 9:51-57.

Wiegand, T., K. A. Moloney, J. Naves, and F. Knauer. 1999. Finding the missing link between landscape structure and population dynamics: a spatially explicit perspective. American Naturalist 154:605-627.

Wiegand, T., E. Revilla, and K. A. Moloney. 2005. Effects of habitat loss and fragmentation on population dynamics. Conservation Biology 19: 108-121.

World Conservation Union (IUCN). 1998. Guidelines for re-introductions. IUCN, Gland, Switzerland. 